\title{
Epidemiology of malaria in the forest-savanna transitional zone of Ghana
}

\author{
Seth Owusu-Agyei*1,2, Kwaku Poku Asante ${ }^{1}$, Martin Adjuik ${ }^{3}$, George Adjei ${ }^{1}$, \\ Elizabeth Awini ${ }^{4}$, Mohammed Adams1', Sam Newton1, David Dosoo1, \\ Dominic Dery ${ }^{1}$, Akua Agyeman-Budu ${ }^{1}$, John Gyapong ${ }^{5}$, Brian Greenwood ${ }^{2}$ \\ and Daniel Chandramohan ${ }^{2}$
}

\author{
Address: ${ }^{1}$ Kintampo Health Research Centre, Kintampo, Ghana, ${ }^{2}$ DCVB/ITD, London School of Hygiene \& Tropical Medicine, UK, ${ }^{3}$ Navrongo \\ Health Research Centre, Navrongo, Ghana, ${ }^{4}$ Dodowa Health Research Centre, Dodowa, Ghana and ${ }^{5}$ Health Research Unit, Ghana Health Service, \\ Ghana \\ Email: Seth Owusu-Agyei* - seth.owusu-agyei@kintampo-hrc.org; Kwaku Poku Asante - kwakupoku.asante@kintampo-hrc.org; \\ Martin Adjuik - MAdjuik@navrongo.mimcom.net; George Adjei - george.adjei@kintampo-hrc.org; \\ Elizabeth Awini - Awini.elizabeth@gmail.com; Mohammed Adams - mohammed.adams@kintampo-hrc.org; \\ Sam Newton - sam.newton@kintampo-hrc.org; David Dosoo - david.dosoo@kintampo-hrc.org; Dominic Dery - dominic.dery@kintampo- \\ hrc.org; Akua Agyeman-Budu - akua.agyeman-budu@kintampo-hrc.org; John Gyapong - John.Gyapong@ghs-hru.org; \\ Brian Greenwood - Brian.Greenwood@lshtm.ac.uk; Daniel Chandramohan - Daniel.Chandramohan@lshtm.ac.uk \\ * Corresponding author
}

Published: 28 September 2009

Malaria Journal 2009, 8:220 doi:10.1 186/1475-2875-8-220
Received: 30 January 2009

Accepted: 28 September 2009

This article is available from: http://www.malariajournal.com/content/8/I/220

(C) 2009 Owusu-Agyei et al; licensee BioMed Central Ltd.

This is an Open Access article distributed under the terms of the Creative Commons Attribution License (http://creativecommons.org/licenses/by/2.0), which permits unrestricted use, distribution, and reproduction in any medium, provided the original work is properly cited.

\begin{abstract}
Background: Information on the epidemiology of malaria is essential for designing and interpreting results of clinical trials of drugs, vaccines and other interventions. As a background to the establishment of a site for anti-malarial drugs and vaccine trials, the epidemiology of malaria in a rural site in central Ghana was investigated.

Methods: Active surveillance of clinical malaria was carried out in a cohort of children below five years of age $(n=335)$ and the prevalence of malaria was estimated in a cohort of subjects of all ages $(n=1484)$ over a 12 -month period. Participants were sampled from clusters drawn around sixteen index houses randomly selected from a total of about 22,000 houses within the study area. The child cohort was visited thrice weekly to screen for any illness and a blood slide was taken if a child had a history of fever or a temperature greater than or equal to 37.5 degree Celsius. The all-age cohort was screened for malaria once every eight weeks over a 12-month period. Estimation of Entomological Inoculation Rate (EIR) and characterization of Anopheline malaria vectors in the study area were also carried out.
\end{abstract}

Results: The average parasite prevalence in the all age cohort was $58 \%(95 \% \mathrm{Cl}: 56.9,59.4)$. In children below five years of age, the average prevalence was $64 \%(95 \% \mathrm{Cl}: 61.9,66.0)$. Geometric mean parasite densities decreased significantly with increasing age. More than $50 \%$ of all children less than 10 years of age were anaemic. Children less than 5 years of age had as many as seven malaria attacks per child per year. The attack rates decreased significantly with increasing cut-offs of parasite density. The average Multiplicity of Infection (MOI) was of 6.I. All three pyrimethamine resistance mutant alleles of the Plasmodium falciparum $\mathrm{dhfr}$ gene were prevalent in this population and $25 \%$ of infections had a fourth mutant of pfdhps-A437G. The main vectors were Anopheles funestus and Anopheles gambiae and the EIR was 269 infective bites per person per year.

Conclusion: The transmission of malaria in the forest-savanna region of central Ghana is high and perennial and this is an appropriate site for conducting clinical trials of anti-malarial drugs and vaccines. 


\section{Background}

Over 500 million episodes of malaria occur yearly, predominantly in sub-Saharan African children under five years of age, resulting in the death of approximately a million of these children [1-3]. Severe anaemia due to malaria occurs in 1.5 to 6.0 million African children per year with a case fatality rate of about $10 \%$; respiratory distress, hypoglycaemia and overlapping conditions contribute a further 1-2 million cases with a mortality of nearly $20 \%$ [4]. In Ghana, malaria has been [5], and remains the first cause of loss of days of healthy life [6] as it accounts for at least $20 \%$ of child deaths, $40 \%$ of child hospital admissions and more than $50 \%$ of out-patient attendances [6].

Knowledge of the epidemiology of malaria is essential for the design and interpretation of the results of trials of drugs, vaccines and other anti-malarial interventions [710]. Information required includes data on parasite prevalence and parasite genetic characteristics, the dynamics of the infection, attack rates, antigenic variability, the nature, behaviour and genetic characteristics of the local malaria vectors and information on patterns of morbidity from malaria. Prior to the conduct of a series of drug and vaccine trials, a study of the epidemiology of malaria were carried out in a forest area of central Ghana, an area where a few malaria studies have been done in recent years.

\section{Methods}

\section{Study Site}

Kintampo North and South districts lie within the forestsavanna, transitional ecological zone in the Brong Ahafo Region of Ghana. The districts have an area of 7,162 km² and a population of approximately 150,000 living in 97 communities. The mean monthly temperature ranges between $18^{\circ} \mathrm{C}$ and $38^{\circ} \mathrm{C}$ and the average rainfall is 1250 mm per annum, occurring mainly between May and October each year.

\section{Study participants selection}

Three hundred and thirty-five children below five years of age (child cohort) and 1,484 participants of all ages (allage cohort) from the study areas were enrolled. They came from sixteen "index houses" selected randomly from the 22,000 houses within the study area that are registered in a database of an ongoing health and demographic surveillance system. The houses were stratified initially into three micro-ecological areas (urban, rural savanna and forest) and weighted such that the number of houses selected from each of these areas was proportional to the target population in each stratum and that only one "index house" was selected from each village. From each "index house", all children less than 10 years of age and a weighted number of 10-19 years and above 19+ years old adults were selected. If an "index house" did not have the required number of participants per age group, nearby houses were visited in order of proximity to the "index house" until the required number for each age category was obtained. An "index cluster", our unit of sampling, formed the cluster of contiguous houses in which recruitment took place. An average of 87 houses represented a cluster. In total, there were 1113 participants in the age group less than 10 years weighted in each cluster, 167 in the 10-19 years age group and 204 participants in the 19+ years age-group. Study participants were recruited in November and December 2003 and followed up over a 12-month period.

\section{Active surveillance for incidence of clinical malaria}

The child cohort was visited at home thrice weekly to check the axillary temperature and to enquire about any recent illness. If a child had an axillary temperature $\geq$ $37.5^{\circ} \mathrm{C}$ or a history of fever within the past 48 hours as reported by the caregivers, the symptoms and signs of the illness were recorded and a finger-prick blood sample was collected to measure haemoglobin concentration and to prepare a blood smear. Children who had an axillary temperature $\geq 37.5^{\circ} \mathrm{C}$ or a history suggestive of malaria and malaria parasitaemia were treated with sulphadoxinepyrimethamine (SP), the second line drug for management of uncomplicated malaria and allowed the clinician's judgement to prevail. Participants were observed at days 7, 14 and 28 post-treatment to assess clearance of malaria parasites as well as resolution of symptoms. Children who had a negative smear, had a repeat blood smear taken on the following day and were treated with SP if positive for malaria. If a repeat smear was negative and symptoms had subsided, the thrice-weekly examination of temperature and history taking was resumed. If symptoms persisted, daily temperature measurements, blood smears and evaluation by the medical staff continued. Symptomatic patients with negative smears were evaluated for other conditions beside malaria, treated appropriately and followed up. A referral system to the regional hospital was put in place for any child whose condition deteriorated.

\section{Malaria Surveys}

The all-age cohort was surveyed once every eight weeks over the one- year study period. At each survey, axillary temperature and a finger prick blood sample was collected to measure haemoglobin concentration using a calibrated haemocue (HaemoCue GmbH, Germany) and to test for malaria parasites. A medical history was obtained and physical examinations performed; information was also collected on use of a bed net by each participant.

\section{Examination of blood smears}

Thin and thick blood smears were stained with Giemsa after fixing the thin smear with methanol. At least 100 
high power fields were examined before a thick smear was declared negative. The number of parasites per micro-litre approximately equals 40 times the number of parasites counted per 200 leukocytes. $10 \%$ random selections of smears were independently read by an experienced second reader to ascertain the quality of microscopy. There was a high level of correlation between the microscopists $($ kappa $=0.94)$.

\section{Polymerase Chain Reaction (PCR)}

Baseline assessment of chloroquine and SP resistance molecular markers and multiplicity of infection was carried out. Parasite DNA was extracted using the Chelex 100 sodium form (Bio-Rad laboratories) according to the procedure previously described [11]. This DNA was used in primary and secondary (nested) PCR analyses to detect and characterize mutations in the Plasmodium falciparum chloroquine resistance transporter ( $p f c r t)$ and multi-drug resistance ( $p f m d r 1$ ) genes. Polymorphisms in the dihydrofolate reductase $(d h f r)$ and dihydropteroate synthase (dhps) genes were also determined by nested PCR amplifications, and dot blot hybridization as previously described by Noedl et al [12] and Duraisingh et al [13]. Polymorphic repetitive regions of block 3 of Merozoite Surface Protein-2 ( $m s p 2)$ were used for genotyping the Plasmodium falciparum isolates using a nested PCR.

The seasonal distribution of parasites within the all-age cohort was determined in 600 participants microscopically positive for malaria. These randomly selected filter paper samples were taken through DNA extraction and analysis, using the chelex method and MSP2 genotyping of Plasmodium falciparum as described above. Filtermats were collected from children who were treated with SP for clinical malaria episodes and actively followed up to ascertain the treatment outcome. DNA was extracted from filtermats with corresponding microscopically slide positive samples on the day of treatment (Day Zero), negative on Day 14 and positive on Day 28 after treatment and analysed using the methods developed and routinely used at LSHTM $[14,15]$ described above.

\section{Estimation of malaria transmission using entomological inoculations rates}

CDC light traps were used to collect mosquitoes in rooms of randomly selected households. Trapping was done a day before the malaria survey in each cluster. All houses within the study area were given equal chances of participation. They were selected without replacement until all houses within a stratified area had been considered. Traps were set in at least four houses in each cluster each month. Additional traps were set weekly in rooms of study participants included in the child cohort or the all age cohort ensuring that at least one trapping took place in each month in each of the sixteen (16) clusters and throughout the whole one year period of the study. A total of 664 successful light traps were set in 708 houses. Occupants of each room in which a trap was set were provided with an untreated bed net to be used for the night that the trap was set in his/her room. Traps were hung approximately $1.5 \mathrm{~m}$ above the floor at the foot of the bed/mat of the index person. Anopheline vectors were morphologically characterized by species using keys [16], stored in $1.5 \mathrm{ml}$ microcentrifuge tubes enclosed in zip lock plastic bags with silica gel. A maximum of ten vectors of the same species from the same compound was put in a tube. Non-Anophelines were discarded after recording numbers caught.

Heads and thoraces of the two major vectors of malaria, Anopheles gambiae and Anopheles funestus, were checked for the presence of circumsporozoite (CS) antigens of Plasmodium falciparum using the sandwiched Enzyme-Linked Immunosorbent Assay (ELISA) as described by Wirtz et al [17]. Presence of CSP in the mosquitoes was read at 405 $\mathrm{nm}$ wavelength using a micro plate ELISA reader. A cut-off of $0.2 \mathrm{~nm}$ absorbance was considered positive after subtraction of an average value from seven negative test mosquitoes. Heads and thoraces of male Anopheles vectors were used as the negative test controls. All positive tested mosquitoes were retested to confirm positives.

Sub-samples of An. gambiae species were subjected to PCR analysis to identify sibling species within the complex as per the Scott et al protocol [18]. Enzyme digestion to differentiate the molecular forms of An. gambiae s.s. was performed as per the protocol of Flavia et al [19]. The presence of $k d r$ alleles associated with knock-down resistance in West Africa was assessed, as described in the Martínez-Torres et al protocol [20]. An adjustment to protocols for optimization and to suit local laboratory conditions was done when necessary.

\section{Sample size calculation}

The sample size calculation was based on our assumed estimates of the age-group specific parasite prevalence rates (p) and standard error (s) among children less than 5 years $(\mathrm{p}=84 \%, \mathrm{~s}=0.03893), 5-10$ years $(\mathrm{p}=92 \%, \mathrm{~s}=$ $0.02845), 10-19$ years $(\mathrm{p}=64 \%, \mathrm{~s}=0.05242)$, and more than 19 years $(\mathrm{p}=51 \%, \mathrm{~s}=0.05242)$. A minimum number of 140 volunteers was estimated in each age group to represent a cluster. This allowed us to estimate the age specific parasite prevalence rates to within $6-10 \%$ of the true values for the different age groups. The expected precision of the estimates were calculated using the formulae of Bennett et al [21].

\section{Data management and statistical analysis}

All data collected in the field or the laboratory were logged for traceability, and then batched for double data entry and processing using Microsoft ${ }^{\circledR}$ Visual FoxPro 6.0. All 
data management processes were done at the computer laboratory of the Kintampo Health Research Centre. Data analysis was done using StataCorp Stata 9, TX USA. Moving averages and proportions were used to provide descriptions of age and seasonal variation in parasite prevalence, density, infection rates and the proportions of parasite clones that persisted over the period.

\section{Ethical processes}

The study protocol and instruments were reviewed and approved by the Ghana Health Service Ethics Review Committee and London School of Hygiene and Tropical Medicine Ethics Committee. In each community, a meeting was held among community members, their opinion leaders and the investigators to seek approval for the study to be conducted in the community before the study started. Written consent was sought from each adult participant while care-givers gave a written consent on behalf of their children.

\section{Results}

\section{Prevalence of malaria}

The annual prevalence of malaria over the 12-month period in the all-age cohort was 58\% (95\% CI: 56.9, $59.4 \%$ ) and it ranged from $67.3 \%$ (95\% CI: 64.1, 70.3\%) in May-June to $51.9 \%$ (95\% CI: 49.3, 54.6\%) in November-December. The average annual prevalence in children below five years of age was 64\% (95\% CI: 61.9, 66.0\%) and it ranged from $74.3 \%$ (95\% CI: 68.7, 79.3\%) in MayJune to $56.8 \%$ (95\% CI: $53.0,60.5 \%$ ) in NovemberDecember, a statistically significant difference between the two periods. Parasite prevalence increased with age until about ten years. It was relatively high during the rainy season (May-October) but was high throughout the year (Figure 1). The geometric mean parasite density (GMPD) decreased significantly with age but it remained relatively constant throughout the year for all age groups (Figure 2). There were no statistically significant differences between GMPDs within each age group throughout the year.

\section{Prevalence of anaemia}

The mean haemoglobin concentration in the all-age cohort was $10.67 \mathrm{~g} / \mathrm{dL}$. It was $10.64 \mathrm{~g} / \mathrm{dl}$ in males and $10.71 \mathrm{~g} / \mathrm{dL}$ in females. For the children under-five years of age, the mean was $9.68 \mathrm{~g} / \mathrm{dL}$; children $<2$ year of age had the lowest mean $\mathrm{Hb}$ concentration (8.85 g.dL) (Figure 3 ). Throughout the year, over half of the children less than 10 years of age had a $\mathrm{Hb}<11 \mathrm{~g} / \mathrm{dL}$ (Figure 4). Moderately severe anaemia $(\mathrm{Hb}<8 \mathrm{~g} / \mathrm{dL})$ was highest $(12.6 \%)$ in November/December, the end of the rainy season.

\section{Incidence of clinical malaria}

The incidence density of clinical malaria defined as any level of parasite density plus reported fever/axillary tem-

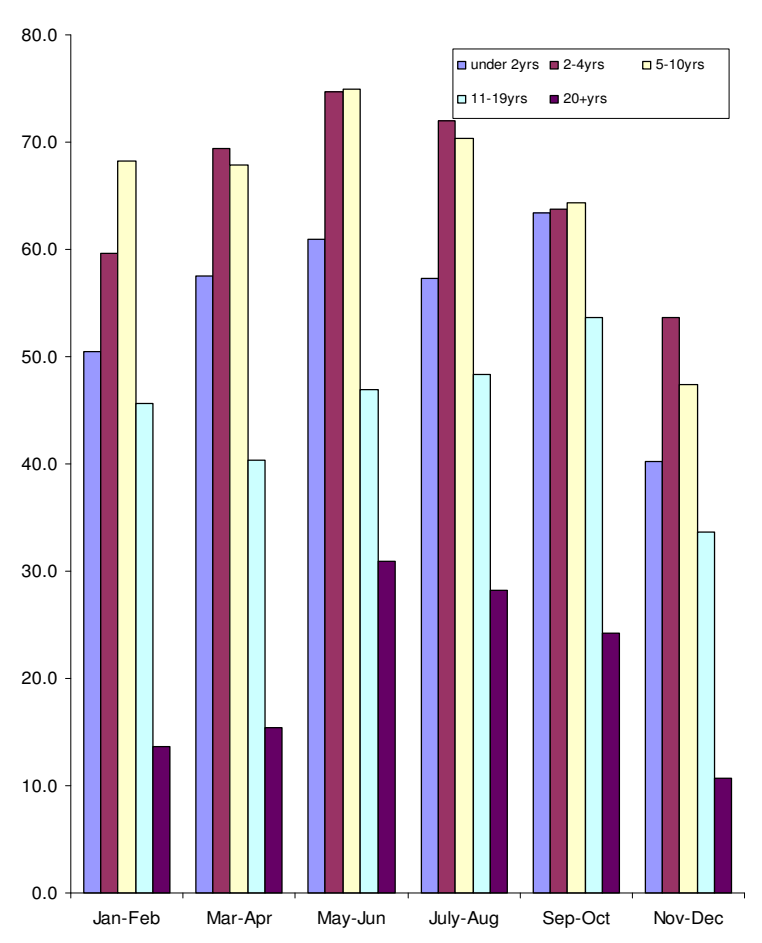

\section{Figure I}

Parasite prevalence by age group and months of survey.

perature $>37.5^{\circ} \mathrm{C}$ among children below five years of age was 7 attacks per child per year. It was 2.3 attacks per year in children below six months of age and peaked in 12-35 month old children (8.6 per child per year). The incidence of malaria with higher parasite density levels was lower than malaria with any parasite density in all age groups (Table 1). The incidence of malaria in children below five

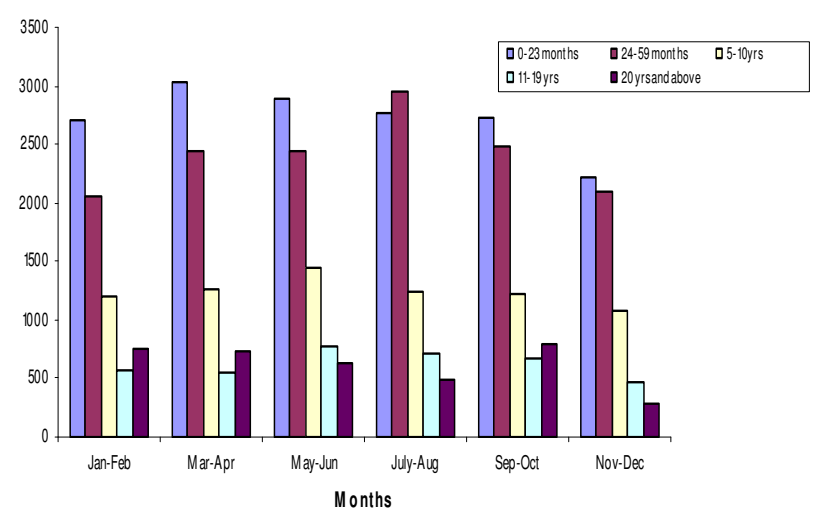

Figure 2

Geometric Mean Parasite Density by age and month of survey. 


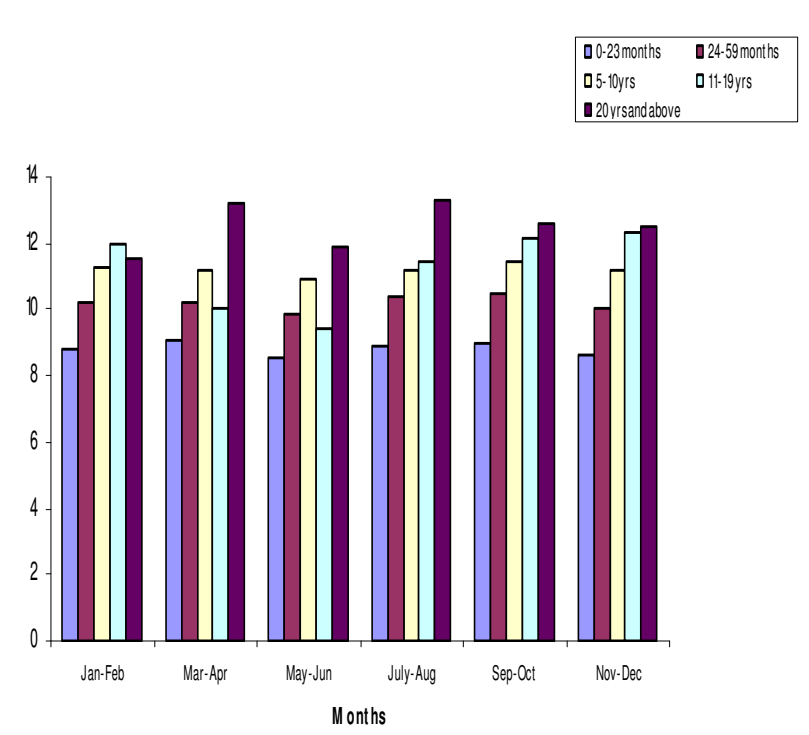

Figure 3

Mean haemoglobin concentration by age and month of survey.

years of age was higher in the rainy season compared to the dry season. The prevalence of fever was significantly higher when parasitaemia cut-off levels increased. For children less than two years of age, incidence density with parasite counts below 5,000/uL was 7.8 compared with 9.5 for parasite counts up to $10,000 / \mu \mathrm{L}$ and still higher (11.3) for parasite counts up to $20,000 / \mu \mathrm{L}$.

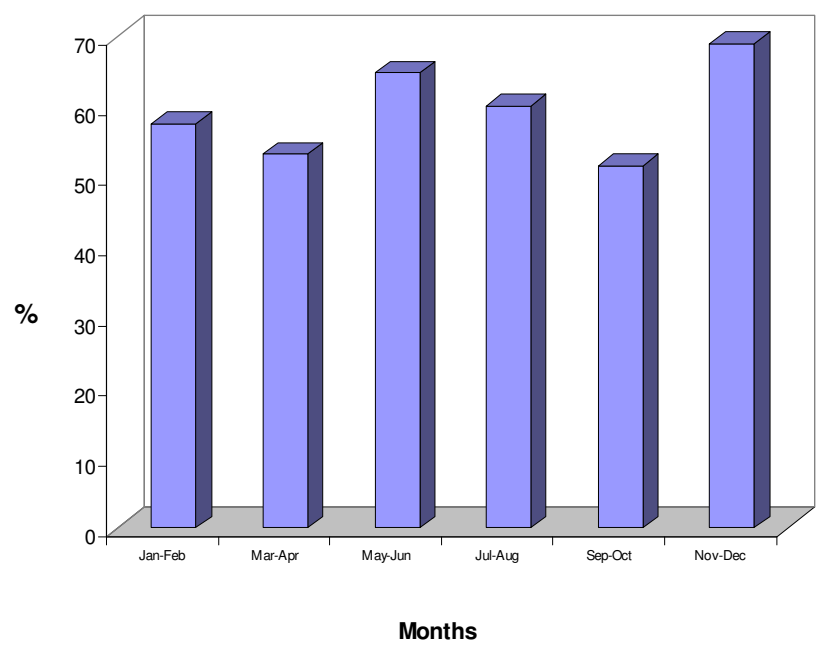

Figure 4

Haemoglobin concentrations by survey round: \% with Hb concentration less than I I g/dL.
In vivo drug sensitivity of commonly used anti-malarials in the study area

For SP, the PCR uncorrected treatment failure rate by day 14 increased from $23.3 \%$ during a first recorded episode to $40.3 \%$ when a child had a fourth or more frequent episode of malaria. Similarly, the treatment failure rate by day 28 increased from $60.8 \%$ for first episodes to $79.8 \%$ for the fourth or more episodes, suggesting a selection for SP resistant parasites by repeated treatment (Table 2 ). The adequate clinical and parasitological response for chloroquine on day 14 was $87.7 \%$ and for day 28 was $77.1 \%$ (Table 3).

\section{Molecular markers for chloroquine and SP resistance and multiplicity of infections}

In a sample of 100 children from whom blood samples were collected prior to treatment, the prevalence of mutations at the pfcrt and pfmdr1 gene loci 76 and 86 were $62.2 \%$ and $60.1 \%$ respectively. The prevalence of mutations at the pfdhfr gene loci 51, 59 and 108 were 51.3\%, $66.2 \%$ and $60.9 \%$ respectively, while the prevalence of mutations at the $p f d h p s$ gene locus 437 was $74.1 \%$. There were 31 isolates harbouring all three mutant alleles of $p f d$ $h f r$ gene. Twenty-five percent of the 31 isolates carried the additional $p f d h p s$ A437G.

In keeping with the high prevalence of infection, the multiplicity of infections (MOI) was high. The MOI peaked in March-April and this trend was seen in children and adults (Figure 5).

\section{Malaria vectors and entomological inoculation rate}

A total of 19,835 mosquitoes were collected from light trap catches during the one year study period and comprised Culex (51.3\%), Aedes (1.0\%), Anopheles funestus (35.2\%), Anopheles gambiae (10.6\%), Anopheles rufipes $(1.8 \%)$ and Anopheles pharoensis (0.1\%). Among the sample of mosquitoes assayed by CS-ELISA, 1.5\% of An. funestus $(\mathrm{n}=6,542)$ and $4.7 \%$ of An. gambiae $(\mathrm{n}=1,876)$ were infected with P. falciparum. No An. arabiensis was found. The estimated annual Entomological Inoculation Rate (EIR) for both An. gambiae and An. funestus vector species was 269 infective bites per person per year $(i b / p / y)$. Infective bites per person per night ranged from $0-13.5$ in the communities (Figure 6). There were variations in EIRs by season and between clusters. EIR peaked during the minor wet season, Nov - April (202 ib/p/y) and became less during the major wet season, May-Oct $(67 i b / p / y)$. Transmission was all-year round, but the two main vectors alternated their peak transmission periods (Figure 7). An. gambiae transmission peaked at the end of the rainy season (November to December) whiles An. funestus transmission peaked during the rains (May to October). This observation reflected in abundance of the vectors as the abundance of An. gambiae was very high at the end of rains 
Table I: Incidence density of clinical malaria* by age group in under five year-old children

\begin{tabular}{|c|c|c|c|}
\hline Age group & Episodes of clinical malaria & Person Years & Incidence density (no. of episodes per child per year) \\
\hline \multicolumn{4}{|c|}{ Any Parasitaemia } \\
\hline $0-6 \mathrm{mth}$ & 36 & 5637 & 2.3 \\
\hline $0-11 \mathrm{mth}$ & 145 & 12301 & 4.3 \\
\hline $12-23$ mth & 310 & 13239 & 8.6 \\
\hline $24-35 \mathrm{mth}$ & 246 & 10618 & 8.5 \\
\hline $36-47 \mathrm{mth}$ & 224 & 11673 & 7.0 \\
\hline $48-59 \mathrm{mth}$ & 133 & 7658 & 6.3 \\
\hline under-five yrs & 1058 & 55489 & 7.0 \\
\hline \multicolumn{4}{|c|}{ Parasitaemia $>5000 / \mu \mathrm{L}$} \\
\hline $0-6 \mathrm{mth}$ & 12 & 5637 & 0.8 \\
\hline $0-11 \mathrm{mth}$ & 77 & $1230 \mid$ & 2.3 \\
\hline $12-23 \mathrm{mth}$ & 222 & 13239 & 6.1 \\
\hline $24-35 \mathrm{mth}$ & 166 & 10618 & 5.7 \\
\hline $36-47 \mathrm{mth}$ & 122 & 11673 & 3.8 \\
\hline $48-59 \mathrm{mth}$ & 69 & 7658 & 3.3 \\
\hline under-five yrs & 656 & 55489 & 4.3 \\
\hline
\end{tabular}

\section{Parasitaemia $>10000 / \mu \mathrm{L}$}

$\begin{array}{lcrr}0-6 \mathrm{mth} & 9 & 5637 & \mathbf{0 . 6} \\ 0-11 \mathrm{mth} & 62 & 12301 & \mathbf{1 . 8} \\ 12-23 \mathrm{mth} & 193 & 13239 & \mathbf{5 . 3} \\ 24-35 \mathrm{mth} & 145 & 10618 & \mathbf{5 . 0} \\ 36-47 \mathrm{mth} & 103 & 11673 & \mathbf{3 . 2} \\ 48-59 \mathrm{mth} & 56 & 7658 & \mathbf{2 . 7} \\ \text { under-five yrs } & \mathbf{5 5 9} & \mathbf{5 5 4 8 9} & \mathbf{3 . 7}\end{array}$

\section{Parasitaemia $>20000 / \mu \mathrm{L}$}

0-6 mth

$0-11 \mathrm{mth}$

$12-23 \mathrm{mth}$

24-35 mth

36-47 mth

48-59 mth

under-five yrs

$\begin{array}{crr}7 & 5637 & \mathbf{0 . 5} \\ 45 & 12301 & 1.3 \\ 146 & 13239 & \mathbf{4 . 0} \\ 108 & 10618 & \mathbf{3 . 7} \\ 80 & 11673 & \mathbf{2 . 5} \\ 46 & 7658 & \mathbf{2 . 2} \\ \mathbf{4 2 5} & 55489 & \mathbf{2 . 8}\end{array}$
0.6
5.3
5.0
3.7

Parasitaemia $>50000 / \mu \mathrm{L}$
$0-6 \mathrm{mth}$
$0-11 \mathrm{mth}$
$12-23 \mathrm{mth}$
$24-35 \mathrm{mth}$
$36-47 \mathrm{mth}$
$48-59 \mathrm{mth}$
under-five yrs

Parasitaemia $>50000 / \mu \mathrm{L}$

$0-6$ mth

$0-1 \mathrm{I}$ th

$12-23 \mathrm{mth}$

under-five yrs

* Clinical malaria $=$ parasitemia at defined levels plus either temperature $\geq 37.5^{\circ} \mathrm{C}$ or reported fever within 48 hours 
Table 2: Proportion of children with malaria parasites within 28 days post treatment with sulphadoxine-pyrimethamine at each episode of malaria

\begin{tabular}{ccccc}
\hline Day of follow up & First episode & Second episode & Third episode & Four or more episodes \\
\hline 7 & $(\mathbf{N}=\mathbf{2 8 8})$ & $(\mathbf{N}=\mathbf{2 3 7})$ & $\mathbf{( N = 1 8 3 )}$ & $\mathbf{( N = 3 8 2 )}$ \\
14 & 24.3 & 22.8 & 20.8 & 29.3 \\
28 & 23.3 & 27.0 & 35.5 & 70.3 \\
\end{tabular}

whiles abundance of An. funestus was very high during the torrential rains (Figure 7). Nonetheless, An. gambiae remained the main vector contributing most to transmission despite the lower abundance of this vector population within the survey period. There were marked variations in EIR between communities, depicting the heterogeneity of the micro-ecology in the forest-savanna fringes of Ghana. Monthly fluctuations in vector densities resulted in variations in inoculation rates by season (Figure 7). Inoculation rates were however sustained throughout the year by the two main vectors.

Species, molecular forms and knock-down resistance (kdr) Only Anopheles gambiae s.s were caught and identified as the predominant Plasmodium falciparum vector; 55 of the species were randomly selected and tested using molecular techniques. In the wet season samples, DNA was amplified successfully in 22 of which $16(88.89 \%)$ were identified as S-molecular forms, two (11.11\%) as Mmolecular forms and one (5.56\%) as a hybrid (S-M) molecular form. The pattern was similar for 33 samples collected in the dry season where $11(68.75 \%)$ were made up of S-molecular forms, two $(12.50 \%)$ of the M-molecular forms and three (18.75\%) were hybrids (S-M)-molecular forms (Table 4). The frequency of $k d r$ resistant genotypes was $0.60 \mathrm{~F}(\mathrm{R})$. The genotypes $k d r^{\mathrm{RR}}$ was observed in the M-molecular form in comparison with the $k d r^{\mathrm{R} / \mathrm{S}}$ genotype which was found in the hybrid (M-S) molecular form. All susceptible genotypes $k d r \mathrm{~s} / \mathrm{S}$ were detected in S-molecular forms (Table 4).

Bed net (treated or untreated) use was low for all age groups. The maximum use of a bed net was found among children less than 5 years of age $(25.4 \%)$. However, $<10 \%$ of the community used treated bed nets throughout the year.

Table 3: Proportion of children with malaria parasitaemia within 28 days post treatment with chloroquine

\begin{tabular}{cc}
\hline Day of follow up & first episode \\
\hline & $(\mathbf{N}=\mathbf{4 5 5})$ \\
7 & 4.2 \\
14 & 12.3 \\
28 & 22.9 \\
\hline
\end{tabular}

\section{Discussion}

The prevalence of malaria is now falling in several parts of Africa [22-25] as the result of scaling up of control interventions such as insecticide-treated bed nets (ITNs) and artemisinin-based combination therapy (ACT) [26,27]. However, this study shows that in the year 2004 the burden of malaria was still very high in the forest/savanna transition of central Ghana. The clinical malaria attack rate and prevalence of malaria in children were very high.

The prevalence of anaemia was very high and consistent with reports in Ghana (84\%) [28] and other African countries [29] where malaria was endemic. The high prevalence of anaemia could also be due to malnutrition, hookworm infection, and sickle cell anaemia. However, the contribution of these illnesses to anaemia in a malaria endemic region has been found to be minimal compared malaria $[30,31]$

The average EIR (269ib/p/y) was also relatively high and transmission was mainly by Anopheles gambiae and Anopheles funestus. An arabiensis had no role in malaria transmission in this area unlike other West-African countries such as Mali [32]. This could be due to the short duration of the dry season in our study area compared to the long duration of dry season in Mali. A similar environmental influence on species survival is demonstrated by the molecular

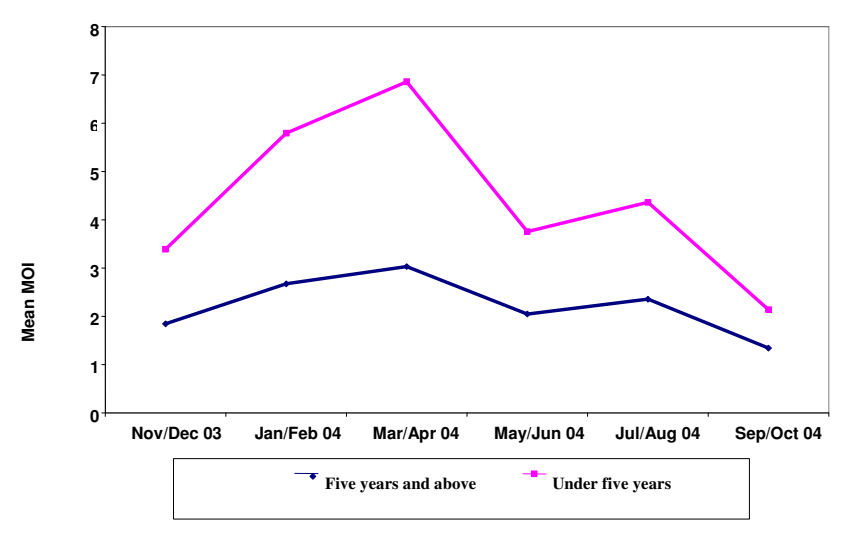

Figure 5

Mean Multiplicity of Infections by season (MOI). 


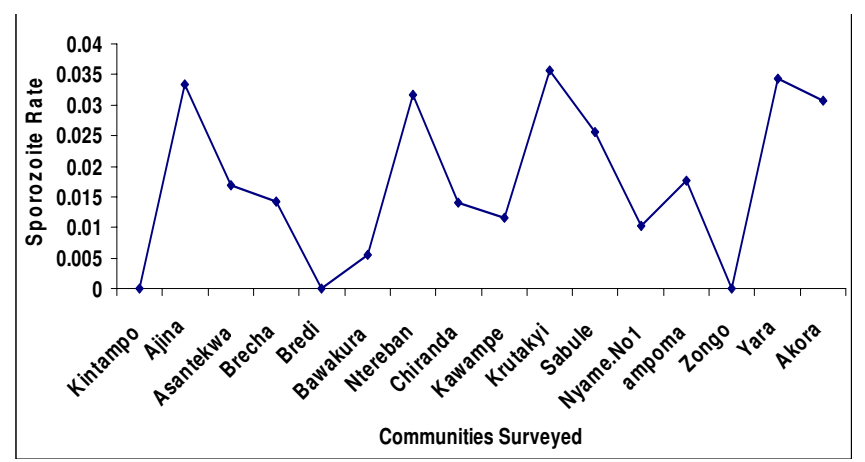

Figure 6

Mean Sporozoite Rates (SR) in communities in Kintampo.

forms of An. gambiae s.s. The S-molecular form was predominant in this area with a short dry season contrary the predominantly $\mathrm{M}$-form found in northern Ghana where the dry season is longer [33]. The presence of low frequency of hybrids suggests the possibility of interbreeding and gradual gene flow within the complex.

A number of factors are likely to underlie the reason why the burden of malaria has remained so high in this part of Ghana despite its relatively high level of prosperity and well-functioning health system. Firstly, the ecosystem is well suited to the survival of An. gambiae and An. funestus with many suitable breeding sites for both species and high humidity persisting throughout the year. Secondly, at the time of this study, attempts at vector control in the area were limited. Coverage with ITNs was low and less than $10 \%$ of the community members used ITNs throughout the year and no indoor residual spraying was taking place. This low coverage was similar to most other rural areas of Ghana where ITNs coverage was on the average about 3.5\% in 2003 as reported in the Ghana Demographic and Health Survey. Thirdly, at the time of the study, clinical malaria was being treated in government facilities and in the private sector primarily with chloroquine or SP. This study demonstrated a high treatment failure rate with both of these drugs, and a high prevalence of mutations associated with resistance to each of these drugs similar to other reports in Ghana [34].

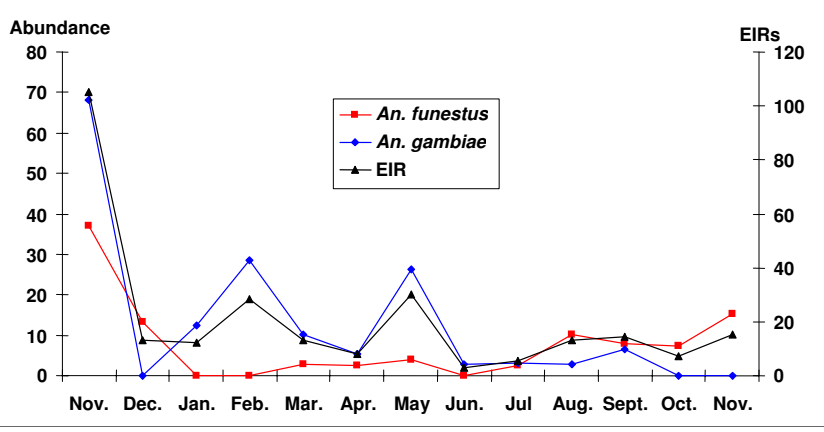

Figure 7

Monthly vector abundance and EIRs in Kintampo Nov 2003- Nov 2004.

Following from the results in this study, steps have been taken to strengthen malaria control in the study area. Use of ITNs has been actively promoted through education and free ITNs distribution. The use of ITNs has increased to $60 \%$ among children less than 5 years and pregnant women in 2007 (Kintampo Health and Demographic Surveillance Systems updates). Since 2005, the first line treatment for malaria has been changed from chloroquine and SP to the more effective drug combination of artesunate plus amodiaquine, although other anti-malarials are still used in the private sector. It is likely that as a result of these interventions the level of malaria transmission has fallen in the study area since the investigations reported in this paper were carried out and therefore a follow-up survey needs to be undertaken. Nevertheless, in comparison to many other parts of Africa, the transmission of malaria remains high in this zone because the background incidence of malaria in children was very high and there is transmission throughout the year. Thus, the Kintampo area is an appropriate site for the conduct of malaria treatment and vaccines trials. Since the completion of this study a clinical trial of artemether-lumefantrine, amodiaquine and artesunate and artesunate + chlorproguanil dapsone [35] and two phase II trials of the malaria vaccine RTS, S have been carried out.

\section{Conclusion}

Findings from this study have facilitated the design of trials of anti-malarial drugs and vaccines in the study area

Table 4: Species, molecular forms and kdr genotypes in An. gambiae s.s in Kintampo

\begin{tabular}{|c|c|c|c|c|c|c|c|c|c|}
\hline \multirow[b]{2}{*}{ Season } & \multicolumn{2}{|c|}{ Species } & \multicolumn{3}{|c|}{ Molecular forms } & \multicolumn{4}{|c|}{ Kdr mutation } \\
\hline & Ag. & Ar. & $\mathbf{M}$ & M/S & $\mathbf{s}$ & $k d r^{R R}$ & $k d r^{\mathrm{R} / S}$ & $k d r \mathrm{SS}$ & $\mathbf{F}(\mathbf{R})$ \\
\hline Wet & 22 & 0 & 2 & 1 & 16 & 3 & I & 1 & 0.60 \\
\hline Dry & 33 & 0 & 2 & 3 & 11 & 3 & 1 & 1 & \\
\hline
\end{tabular}

Hardy-Weinberg expected frequencies not significantly different $\left(P<0.05 ; \mathrm{df}=1 ; \chi^{2}=0.005\right)$ 
and led to optimal interpretation of the results from such trials. On the basis of the background epidemiology of malaria described in this paper, the Kintampo Health Research Centre is well-equipped to contribute to the phase 3 trial of the RTS, S vaccine starting in mid-2009 and future treatment and vaccine trials.

\section{Competing interests}

The authors declare that they have no competing interests.

\section{Authors' contributions}

SOA was the lead in writing the proposal with contribution from KPA, DC, JG and BG. SOA, KP, JG and DC were involved in the planning of the study. SOA, KP, MD, SN and DC implemented the study and data collection. MD, DD, DE and AA analysed laboratory specimen. GA, MA and EL contributed to data management. SOA, KPA, MA, GA, EA, DC and BG contributed to data analysis and presentation. SOA, KPA, DC, BG, DE and AA wrote the manuscript. All authors read and approved the final manuscript.

\section{Acknowledgements}

We are extremely grateful to the participants, parents of the young children involved as well as the community opinion leaders for their interest and support. Sincere thanks go to the management and staff of Kintampo Health Research Centre, the Kintampo Municipal Hospital as well as the Kintampo North and South Health Directorates of the Ghana Health Service. We are grateful to the KHRC-Ethics and Ghana Health Service ethics committees. Our deep appreciation goes to Brian Beard and Anna Randall, both of the London School of Hygiene and Tropical Medicine for their roles in helping to set up the data management and molecular biology systems for this study in KHRC

This study was funded by the Gates Malaria Partnership, London School of Hygiene and Tropical Medicine. Kintampo Health Research Centre is a member-site of the INDEPTH network.

\section{References}

I. Breman JG, Egan A, Keusch GT: The intolerable burden of malaria: a new look at the numbers. Am J Trop Med Hyg 200I, 64:iv-vii.

2. World Health Organisation: The World Health Report. Fighting disease, fostering development. Geneva 1996.

3. World Health Organisation: Guidelines for the evaluation of Plasmodium falciparum vaccines in populations exposed to natural infections. TDR/MAL/VAC/97. Geneva 1997.

4. Murphy SC, Breman JG: Gaps in the childhood malaria burden in Africa: cerebral malaria, neurological sequelae, anemia, respiratory distress, hypoglycemia, and complications of pregnancy. Am J Trop Med Hyg 200I, 64:57-67.

5. Commey JOO, Mills-Tetteh D, Philps BJ: Cerebral malaria in Accra. Ghana Med J 1980, 19:68-72.

6. Ministry of Health/Ghana Health service: Annual Report of the Ghana National Malaria Control Programme. Ghana 2006.

7. Baird JK, Owusu-Agyei S, Utz GC, Koram KA, Barcus MJ, Jones TR, Fryauff DJ, Binka FN, Hoffman SL, Nkrumah FK: Seasonal malaria attack rates in infants and young children in northern Ghana. Am J Trop Med Hyg 2002, 66(3):280-286.

8. Koram KA, Owusu-Agyei S, Utz G, Binka FN, Baird JK, Hoffman SL, Nkrumah FK: Severe anemia in young children after high and low malaria transmission seasons in the Kassena-Nankana district of northern Ghana. Am J Trop Med Hyg 2000, 62:670-674.
9. Owusu-Agyei S, Koram KA, Baird JK, Utz GC, Binka FN, Nkrumah FK, Fryauff DJ, Hoffman SL: Incidence of symptomatic and asymptomatic Plasmodium falciparum infection following curative therapy in adult residents of northern Ghana. Am J Trop Med Hyg 200I, 65(3): 197-203.

10. Owusu-Agyei S, Fryauff DJ, Chandramohan D, Koram KA, Binka FN, Nkrumah FK, Utz GC, Baird JK, Hoffman SL: Characteristics of severe anemia and its association with malaria in young children of the Kassena-Nankana District of Northern Ghana. Am J Trop Med Hyg 2002, 67(4):37I-7.

1I. Wooden J, Kyes S, Sibley CH: PCR and strain identification in Plasmodium falciparum. Parasitology Today 1993, 9:303-305.

12. Noedl H, Wongsrichanalai C, Wernsdorfer HW: Malaria drug-sensitivity testing: new assays, new perspectives. Trends in parasitology 2003, 4:36I.

13. Duraisingh MT, Seidlein VLV, Jepson A, Jones P, Sambou I, Pinder M, Warhurst DC: Linkage disequilibrium between two chromosomally distinct loci associated with increased resistance to Chloroquine in Plasmodium falciparum. Parasitology 2000, 121:1-7.

14. Alloueche A, Silveira H, Conway DJ, Bojang K, Doherty T, Cohen J, Pinder M, Greenwood BM: High-throughput sequence typing of T-cell epitope polymorphisms in Plasmodium falciparum circumsporozoite protein. Mol Biochem Parasitol 2000, 106(2):273-82.

15. Sutherland CJ, Alloueche A, Curtis J, Drakeley CJ, Ord R, Duraisingh M, Greenwood BM, Pinder M, Warhurst D, Targett GA: Gambian children successfully treated with chloroquine can harbor and transmit Plasmodium falciparum gametocytes carrying resistance genes. Am J Trop Med Hyg 2002, 67(6):578-85.

16. Gilles HM, Gilles MT, De Meillon B: The Anophelinae of Africa South of Sahara (Ethiopian Zoogeographical Region). Volume 54. 2nd edition. Publication of the South African Institute for Medical Research; 1968:343.

17. Wirtz R: Comparative testing of Plasmoduim falciparum sporozoite monoclonal antibodies for ELISA development. Bull WHO 1987, 65:39-45.

18. Scott JA, Brogdon WG, Collins FH: Identification of single specimens of the Anopheles gambiae complex by the polymerase chain reaction. Am J Trop Med Hyg 1993, 49(4):520-9.

19. Favia G, della Torre A, Bagayoko M, Lanfrancotti A, Sagnon N, Touré YT, Coluzzi M: Molecular identification of sympatric chromosomal forms of Anopheles gambiae and furhter invidence of their reproductive isolation. Insect Molecular Biology 1997, 6:377-383.

20. Martinez-Torres D, Chandre F, Williamson MS, Darriet F, Berge JB, Devonshire AL, Guillet P, Pasteur N, Pauron D: Molecular characterisation of pyrethroid knockdown resistance $(K d r)$ in the major malaria vector Anopheles gambiae s.s. Insect Molecular Biology 1998, 7(2): 179-184.

21. Bennett $S$, Woods $T$, Liyanage $W$, Smith $D$ : A simplified general method for cluster-sample surveys of Health in developing countries. Rapp Trimest Stat Sanit Mond 1991, 44:98-106.

22. Ceesay SJ, Casals-Pascual C, Erskine J, Anya SE, Duah NO, Fulford AJ, Sesay SS, Abubakar I, Dunyo S, Sey O, Palmer A, Fofana M, Corrah T, Bojang KA, Whittle HC, Greenwood BM, Conway DJ: Changes in malaria indices between 1999 and 2007 in The Gambia: a retrospective analysis. Lancet 2008, 372:1545-54.

23. Killeen GF, Tami A, Kihonda J: Cost-sharing strategies combining targeted public subsidies with private-sector delivery achieve high bednet coverage and reduced malaria transmission in Kilombero Valley, southern Tanzania. BMC Infect Dis 2007, 7:121.

24. Okiro EA, Hay SI, Gikandi PW: The decline in paediatric malaria admissions on the coast of Kenya. Malar J 2007, 6: I5I.

25. O'Meara WP, Bejon P, Mwangi TW, Okiro EA, Peshu N, Snow RW, Newton C, Marsh K: Effect of a fall in malaria transmission on morbidity and mortality in Kilifi, Kenya. Lancet 2008, 372(9649): 1555-1562.

26. Bhattarai A, Ali AS, Kachur SP: Impact of artemisinin-based combination therapy and insecticide-treated nets on malaria burden in Zanzibar. PLoS Med 2007, 4:e309.

27. Cissé B, Sokhna C, Boulanger D, Milet J, Bâ el H, Richardson K, Hallett R, Sutherland C, Simondon K, Simondon F, Alexander N, Gaye O, Targett G, Lines J, Greenwood B, Trape JF: Seasonal intermittent preventive treatment with artesunate and sulfadoxine- 
pyrimethamine for prevention of malaria in Senegalese children: a randomised, placebo-controlled, double-blind trial. Lancet 2006, 367(95 II):659-67.

28. Zaney GD: Causes and prevention of anaemia.

29. Schellenberg D, Schellenberg JR, Mushi A, Savigny D, Mgalula L, Mbuya C, Victora CG: The silent burden of anaemia in Tanzanian children: a community-based study. Bull World Health Organ 2003, $8 I(8): 58 I-90$.

30. Premji Z, Hamisi Y, Shiff C, Minjas J, Lubega P, Makwaya C: Anaemia and Plasmodium falciparum infections among young children in an holoendemic area, Bagamoyo, Tanzania. Acta Tropica 59 1995, 59:55-64.

31. Newton CR, Warn PA, Winstanley PA, Peshu N, Snow RW, Pasvol $G$, Marsh K: Severe anaemia in children living in a malaria endemic area of Kenya. Trop Med Int Health 1997, 2(2):165-78.

32. Toure YT, Traore SF, Sankare O, Snow MY, Coulibaly A, Esposito F, Petrarca V: Perennial transmission of malaria by the Anopheles gambiae complex in a north Sudan Savanna area of Mali. Med \& Vet Entomol 1996, 10(2): 197-199.

33. Appawu MA, Owusu-Agyei S, Dadzie S, Asoala V, Anto F, Koram K, Rogers W, Nkrumah F, Hoffman SL, Fryauff DJ: Malaria transmission dynamics at a site in northern Ghana proposed for testing of malaria vaccines. Trop Med \& Int Health 2004, 9(I): I 64- I 70.

34. Koram KA, Abuaku B, Duah N, Quashie N: Comparative efficacy of antimalarial drugs including ACTs in the treatment of uncomplicated malaria among children under 5 years in Ghana. Acta Trop 2005, 95(3): 194-203.

35. Owusu-Agyei S, Asante KP, Owusu R, Adjuik M, Amenga-Etego S, Dosoo DK, Gyapong J, Greenwood B, Chandramohan D: An open label, randomised trial of artesunate+amodiaquine, artesunate+chlorproguanil-dapsone and artemether-lumefantrine for the treatment of uncomplicated malaria. PLOS ONE 2008, 3(6): 2530 .

Publish with Bio Med Central and every scientist can read your work free of charge

"BioMed Central will be the most significant development for disseminating the results of biomedical research in our lifetime. "

Sir Paul Nurse, Cancer Research UK

Your research papers will be:

- available free of charge to the entire biomedical community

- peer reviewed and published immediately upon acceptance

- cited in PubMed and archived on PubMed Central

- yours - you keep the copyright

Submit your manuscript here:

http://www.biomedcentral.com/info/publishing_adv.asp
BioMedcentral 